\title{
Interactions of the oxygen-dependent antimicrobial system of the human neutrophil with difloxacin, ciprofloxacin, pefloxacin and fleroxacin in the intraphagocytic eradication of Staphylococcus aureus
}

\author{
CONSTANCE E. JANSEN VAN RENSBURG, GISELA JOONE and R. ANDERSON \\ Medical Research Council Unit for the Study of Phagocyte Function, Division of Immunology, Department of
Medical Microbiology, Institute for Pathology, University of Pretoria, Republic of South Africa
}

Summary. The effect of the $\mathrm{O}_{2}$-dependent antimicrobial systems of the human neutrophil on the intraphagocytic activity of difloxacin, ciprofloxacin, pefloxacin and fleroxacin was determined by use of a radioassay with Staphylococcus aureus as the test organism. The fluoroquinolones exhibited good intraphagocytic activity with normal neutrophils. However the intracellular bioactivities of the four antimicrobial agents were substantially less in tests with neutrophils from two patients with chronic granulomatous disease. These observations suggest a synergic interaction between fluoroquinolones and the $\mathrm{O}_{2}$-dependent antimicrobial systems of phagocytes in the eradication of intracellular microbial pathogens.

\section{Introduction}

Immunosuppression may contribute to unsuccessful antimicrobial chemotherapy. The use of a chemotherapeutic agent with intraphagocytic activity in the treatment of immunocompromised individuals infected with intracellular microbial pathogens may be important. We have previously found that the fluorinated piperazinyl quinolones, difloxacin, ciprofloxacin, pefloxacin and fleroxacin, possess intracellular bioactivity (van Rensburg et al., 1989). In the present study we have compared the ability of these fluoroquinolones to eradicate Staphylococcus aureus in neutrophils with intact $\mathrm{O}_{2}-$ dependent antimicrobial systems and neutrophils from two children with chronic granulomatous disease (CGD). CGD is associated with failure of phagocytes to activate $\mathrm{O}_{2}$-dependent antimicrobial systems (Curnutte et al., 1974).

\section{Materials and methods}

\section{Antimicrobial agents}

Difloxacin, ciprofloxacin, pefloxacin and fleroxacin were obtained from the South African affiliates of Abbott Laboratories, Bayer-Miles Ltd, May and Baker Ltd and Roche Ltd respectively. The agents were dissolved in Hanks's Balanced Salts Solution (HBSS; Grand Island Biological Co., NY, USA) buffered to $\mathrm{pH} 7.2$ with

Received 13 July 1989; revised version accepted 12 Oct. 1989.
HEPES (Sigma Chemical Co., St Louis; MO, USA) 1 g/L to achieve final concentrations of 0.5 and $2.5 \mathrm{mg} / \mathrm{L}$.

\section{Bacteria}

A 24-h culture of S. aureus ATCC 25923 in Nutrient Broth (Difco) was washed three times in phosphatebuffered saline and diluted to $2 \times 10^{8} \mathrm{cfu} / \mathrm{ml}$.

\section{Neutrophils}

Venous blood from two healthy volunteers and two patients with CGD was collected into preservative-free heparin ( 5 units $/ \mathrm{ml}$ of blood). The heparinised blood was fractionated by centrifugation ( $400 \mathrm{~g}$ for $15 \mathrm{~min}$ ) on Ficoll (Pharmacia, Uppsala, Sweden) metrizoate cushions. The resultant fraction was sedimented with gelatin $3 \%$ for $30 \mathrm{~min}$ at $37^{\circ} \mathrm{C}$ to remove most of the erythrocytes. The neutrophil-rich supernate was centrifuged at $250 \mathrm{~g}$ for $10 \mathrm{~min}$ and the residual erythrocytes in the cell pellet were lysed by exposure to ammonium chloride $0.85 \%$. The neutrophils were centrifuged, washed once and resuspended in HBSS to a concentration of $1 \times 10^{7} / \mathrm{ml}$.

\section{Radioassay}

Intracellular bioactivity of the antimicrobial agents was measured as described previously (Anderson et al., 1986). Human neutrophils were pre-incubated with $S$. aureus at a ratio of 1 neutrophil: 20 bacterial cfu for $30 \mathrm{~min}$ at $37^{\circ} \mathrm{C}$ in a final volume of $1 \mathrm{ml}$ of $\mathrm{HBSS}$ containing autologous serum $10 \%$ and $5 \times 10^{6}$ neutrophils. The mixtures of neutrophils and bacteria were rotated on 
a turntable during the 30-min incubation period; lysostaphin $10 \mathrm{mg} / \mathrm{L}$ was added and the tubes were incubated for a further $15 \mathrm{~min}$ at $37^{\circ} \mathrm{C}$. The neutrophils and phagocytosed bacteria were then centrifuged $(250 \mathrm{~g}$ for $10 \mathrm{~min}$ ) and washed to remove the extracellular bacteria. Antimicrobial agents were added to the neutrophils and intracellular bacteria after phagocytosis to achieve a final concentration of 0.5 or $2.5 \mathrm{mg} / \mathrm{L}$. These mixtures were incubated for $4 \mathrm{~h}$ at $37^{\circ} \mathrm{C}$ after which the neutrophils were washed three times in phosphate-buffered saline $(0.15 \mathrm{M}, \mathrm{pH} 7.2)$ to remove the antibiotics and the intracellular bacteria were released by lysis of the neutrophils with distilled water. Nutrient broth containing $5 \mu \mathrm{Ci}$ of a radiolabelled amino acid mixture [ $\mathrm{L}$-amino acid mixture, $\mathrm{L}^{-14} \mathrm{C}(\mathrm{U})$, specific activity $55 \mathrm{mCi} / \mathrm{milli}$ atom carbon, New England Nuclear Corp.] was inoculated with $100 \mu \mathrm{l}$ of the lysate and incubated at $37^{\circ} \mathrm{C}$ for $5 \mathrm{~h}$, after which the bacteria were centrifuged and washed three times in PBS. The extent of incorporation of radiolabelled amino acids into bacterial cells was measured in a liquid scintillation counter (Isocap/300, Searle, Chicago, IL, USA) spectrophotometer. The results were expressed as uptake of radiolabelled amino acids as radioactive counts/min (cpm). Neutrophils were omitted from identically processed control systems containing bacteria and antibiotics only.

\section{Neutrophil viability}

Neutrophil viability was determined before phagocytosis and after the 4-h incubation period of the neutrophils and intracellular bacteria with and without antibiotics by standard dye exclusion methods.

\section{Results}

In tests of neutrophils from healthy volunteers with intact $\mathrm{O}_{2}$-dependent antimicrobial systems, the antimicrobial agents at concentrations of 0.5 and $2.5 \mathrm{mg} / \mathrm{L}$ decreased the survival of intracellular bacteria. There was evidence of a fall in survival of bacteria in all cases except with fleroxacin tested at $0.5 \mathrm{mg} / \mathrm{L}$ (figure). Considerably less antimicrobial activity was obtained in similar experiments with neutrophils from patients with CGD. Evidence of decreases in bacterial growth at an antimicrobial concentration of $2.5 \mathrm{mg} / \mathrm{L}$ (figure) was obtained only with ciprofloxacin and difloxacin.

Exposure of $S$. aureus to pefloxacin and fleroxacin at a concentration of $2.5 \mathrm{mg} / \mathrm{L}$ in HBSS for $4 \mathrm{~h}$ at $37^{\circ} \mathrm{C}$ in the absence of neutrophils did not significantly affect bacterial growth. However, difloxacin and ciprofloxacin, at $2.5 \mathrm{mg} / \mathrm{L}$ in the absence of neutrophils, caused 76.0 (SE 2.8) \% and 57.5 (SE $9 \cdot 2) \%$ reduction in bacterial growth respectively.

No detectable loss of viability of neutrophils was demonstrated when the cells, containing intracell-
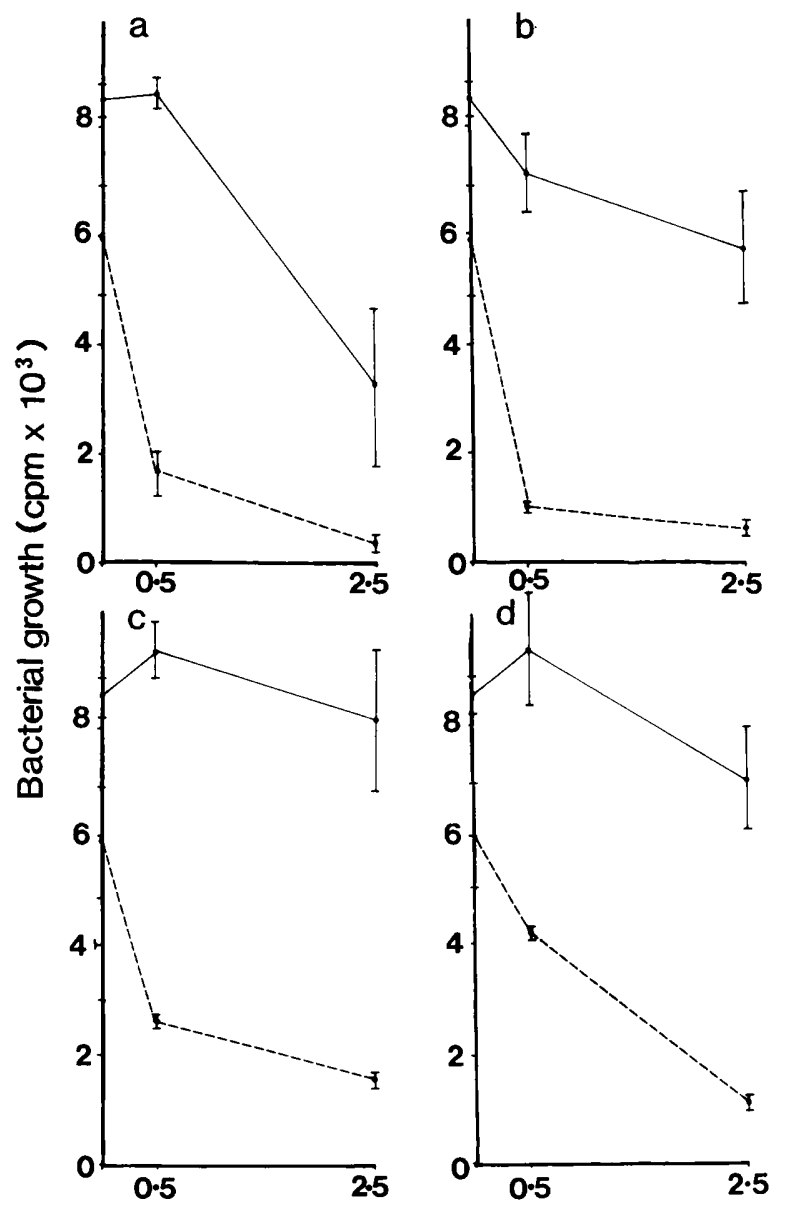

Antibiotic concentration (mg/L)

Figure. Measurement of the intracellular bioactivity of (a) difloxacin, (b) ciprofloxacin, (c) pefloxacin and (d) fleroxacin with the radioassay and $S$. aureus as the target intraphagocytic pathogen. Normal neutrophils (------ $)$ as well as CGD neutrophils (_- ) were used in these experiments. Data are mean values from two different experiments; bars are \pm SEM.

ular bacteria, were incubated with and without antibiotic for $4 \mathrm{~h}$ at $37^{\circ} \mathrm{C}$.

\section{Discussion}

Investigations of the intracellular bioactivity of antimicrobial agents have mainly been done on neutrophils with an intact $\mathrm{O}_{2}$-dependent antimicrobial system (Vosbeck et al., 1984) without taking into account possible interactions between this system and the drug. Use of antimicrobial agents which need an intact intraphagocytic $\mathrm{O}_{2}$-dependent antimicrobial system for optimal intracellular effectiveness may lead to less efficient eradication of 
intracellular pathogens from patients such as those with CGD, in whom the oxidative system of neutrophils is defective. In previous studies we have found that the intracellular bioactivity of amoxycillin, clindamycin, erythromycin and roxithromycin is optimal with normal neutrophils and much less efficient with CGD neutrophils (Anderson et al., 1986, 1987) indicating that the cooperative interactions between the $\mathrm{O}_{2}$-dependent antimicrobial systems of the neutrophil and the intracellular antibiotic should not be under-rated.

We have previously found the radioassay used in the present study to be more sensitive than colony counting procedures (Anderson et al., 1986). All four fluoroquinolones tested, at concentrations of 0.5 and $2.5 \mathrm{mg} / \mathrm{L}$, were found to possess intracellular activity against $S$. aureus in phagocytes with an intact $\mathrm{O}_{2}$-dependent antimicrobial system. However, when CGD-neutrophils were used, only difloxacin and ciprofloxacin exhibited intraphagocytic activity against the test organism and only at a concentration of $2.5 \mathrm{mg} / \mathrm{L}$. This suggests that the

\section{REFERENCES}

Anderson R, Joone G, van Rensburg C E J 1986 An in vitro investigation of the intracellular bioactivity of amoxicillin, clindamycin and erythromycin for Staphylococcus aureus. Journal of Infectious Diseases 153: 593-600.

Anderson R, van Rensburg C E J, Joone G, Lukey P T 1987 An in-vitro comparison of the intraphagocytic bioactivity of erythromycin and roxithromycin. Journal of Antimicrobial Chemotherapy 20 Suppl B : 57-68.

Curnutte J T, Whitten D M, Babior B M 1974 Defective superoxide production by granulocytes from patients with therapeutic efficacy of pefloxacin and fleroxacin may be decreased in individuals with impaired phagocyte functions. The MICs of the fluoroquinolones for $S$. aureus ATCC 25923 were $0.25 \mathrm{mg} / \mathrm{L}$ (difloxacin and ciprofloxacin) and $0.5 \mathrm{mg} / \mathrm{L}$ (pefloxacin and fleroxacin) (van Rensburg et al., 1989). In a neutrophil-free system only ciprofloxacin and difloxacin, but not pefloxacin and fleroxacin, effectively decreased bacterial growth at a concentration of $2.5 \mathrm{mg} / \mathrm{L}$. Therefore, the differences in intracellular activity between the drugs could be ascribed to differences in activity against $S$. aureus. Although a concentration of $2.5 \mathrm{mg} / \mathrm{L}$ is achievable in serum with normal dosages of most of the fluoroquinolones (Eggleston and Park, 1987) these findings stress the importance of obtaining high enough serum levels to optimise interactions with phagocytes.

These results suggest the existence of beneficial interactions between fluoroquinolones and the $\mathrm{O}_{2}$ dependent antimicrobial systems of phagocytes in the eradication of intracellular pathogens.

chronic granulomatous disease. New England Journal of Medicine 290: 593-597.

Eggleston M, Park S Y 1987 Review of the 4-quinolones. Infection Control 8: 119-125.

van Rensburg C E J, Joone G, Anderson R 1989 An in vitro investigation of the intraphagocytic bioactivity of difloxacin, ciprofloxacin, pefloxacin and fleroxacin. International Journal of Chemotherapy 35: 273-277.

Vosbeck K, James P R, Zimmermann W 1984 Antibiotic action on phagocytosed bacteria measured by a new method for determining viable bacteria. Antimicrobial Agents and Chemotherapy 25: 735-741. 